\title{
Continental-scale impacts of intra-seasonal rainfall variability on simulated ecosystem responses in Africa
}

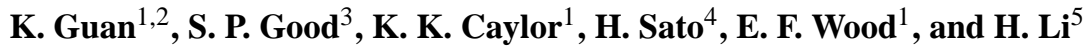 \\ ${ }^{1}$ Department of Civil and Environmental Engineering, Princeton University, Princeton, NJ, USA \\ ${ }^{2}$ Department of Environmental Earth System Science, Stanford University, Stanford, CA 94025, USA \\ ${ }^{3}$ Department of Geology and Geophysics, University of Utah, Salt Lake City, UT 84112, USA \\ ${ }^{4}$ Graduate School of Environmental Studies, Nagoya University, D2-1(510) Furo-cho, Chikusa-ku, Nagoya, \\ Aichi 464-8601, Japan \\ ${ }^{5}$ Department of Earth and Planetary Sciences, Rutgers University, Piscataway, NJ 08854, USA \\ Correspondence to: K. Guan (kaiyug@stanford.edu)
}

Received: 9 April 2014 - Published in Biogeosciences Discuss.: 27 May 2014

Revised: 18 October 2014 - Accepted: 7 November 2014 - Published: 11 December 2014

\begin{abstract}
Climate change is expected to modify intraseasonal rainfall variability, arising from shifts in rainfall frequency, intensity and seasonality. These intra-seasonal changes are likely to have important ecological impacts on terrestrial ecosystems. Yet, quantifying these impacts across biomes and large climate gradients is largely missing. This gap hinders our ability to better predict ecosystem services and their responses to climate change, especially for arid and semi-arid ecosystems. Here we use a synthetic weather generator and an independently validated vegetation dynamic model (SEIB-Dynamic Global Vegetation Model, DGVM) to virtually conduct a series of "rainfall manipulation experiments" to study how changes in the intra-seasonal rainfall variability affect continent-scale ecosystem responses across Africa. We generate different rainfall scenarios with fixed total annual rainfall but shifts in (i) frequency vs. intensity, (ii) rainy season length vs. frequency, (iii) intensity vs. rainy season length. These scenarios are fed into SEIBDGVM to investigate changes in biome distributions and ecosystem productivity. We find a loss of ecosystem productivity with increased rainfall frequency and decreased intensity at very low rainfall regimes $\left(<400 \mathrm{~mm} \mathrm{year}^{-1}\right)$ and low frequency $\left(<0.3\right.$ event day $\left.^{-1}\right)$; beyond these very dry regimes, most ecosystems benefit from increased frequency and decreased intensity, except in the wet tropics ( $>1800 \mathrm{~mm}$ year $^{-1}$ ) where radiation limitation prevents further productivity gains. This result reconciles seemingly contradictory findings in previous field studies on the impact of
\end{abstract}

rainfall frequency/intensity on ecosystem productivity. We also find that changes in rainy season length can yield more dramatic ecosystem responses compared with similar percentage changes in rainfall frequency or intensity, with the largest impacts in semi-arid woodlands. This study demonstrates that intra-seasonal rainfall characteristics play a significant role in influencing ecosystem function and structure through controls on ecohydrological processes. Our results suggest that shifts in rainfall seasonality have potentially large impacts on terrestrial ecosystems, and these understudied impacts should be explicitly examined in future studies of climate impacts.

\section{Introduction}

Due to increased water holding capacity in the atmosphere as a consequence of global warming (O'Gorman and Schneider, 2009), rainfall is projected to change in intensity and frequency across much of the world (Easterling et al., 2000; Trenberth et al., 2003; Chou et al., 2013), in conjunction with complex shifts in rainfall seasonality (Feng et al., 2013; Seth et al., 2013). These changes possibly indicate a large increase in the frequency of extreme events and variability in rainfall (Easterling et al., 2000; Allan and Soden, 2008), and many of these changes may be accompanied with little change in total annual rainfall (Knapp et al., 2002; Franz et al., 2010). However, how these rainfall changes would propagate to various 
terrestrial ecosystems remains less clear. Meanwhile, regions sharing similar total annual rainfall amounts can receive rainfall in very different ways (i.e., different intra-seasonal variabilities). For example, west Africa and southwest Africa (Fig. 1) have similar total annual rainfall, but west Africa has much more intense rainfall events within a much shorter rainy season, while southwest Africa has a longer and less intense rainy season. The same amount of total rainfall but with different intra-seasonal variabilities can form distinctive ecosystem structures and response. However, the ecological significance of intra-seasonal climate variabilities in terrestrial biogeography has been largely overlooked (Good and Caylor, 2011). Understanding these impacts and their possible future changes on terrestrial ecosystems is critical for maintaining ecosystem services and planning adaptation and mitigation strategies for ecological and social benefits under climate change (Anderegg et al., 2013), especially for arid and semi-arid regions, which covers one third of the land surface.

Previous studies have addressed certain aspects of the terrestrial ecosystem responses to the intra-seasonal rainfall variability (Porporato et al., 2001; Weltzin et al., 2003; Williams and Albertson, 2006; Good and Caylor, 2011; Guan et al., 2014), but they are limited in the following aspects. First, existing field studies mostly focus on a single ecosystem, i.e., grasslands, and subsequently only low rainfall regimes have been examined to date (mostly below $800 \mathrm{~mm}_{\text {year }}{ }^{-1}$, see Table 1). Grasslands have the largest sensitivity to hydrological variabilities among all natural ecosystems (Scanlon et al., 2005; Guan et al., 2012); however, inferences drawn from a single ecosystem are limited in scope and difficult to apply to other ecosystems. Second, even within grasslands, different studies have seemingly contradictory findings (see Table 1), and there is a lack of a comprehensive framework to resolve these inconsistencies. Specifically, whether increased rainfall intensity with decreased rainfall frequency has positive (Knapp et al., 2002; Fay et al., 2003; Robertson et al., 2009; Heisler-White et al., 2009) or negative impacts (Heisler-White et al., 2009; Thomey et al., 2011) on grassland productivity is still under debate. Third, previous studies mostly focus on the impacts of rainfall frequency and intensity (Table 1 and RodríguezIturbe and Porporato, 2004), and largely overlook the possible changes in rainfall seasonality (i.e., rainy season length in particular). Rainfall frequency and intensity mostly describe rainfall characteristics within the rainy season, but do not account for the impacts of interplay between rainy season and dry season (Guan et al., 2014). For ecosystems predominately controlled by water availability, rainy season length constrains the temporal niche for active plant physiological activities (van Schaik et al., 1993; Scholes and Archer, 1997). Paleoclimate pollen records (e.g., Vincens et al., 2007) confirm that large variations in rainfall seasonality can lead to significant shifts in biome distribution. Given that changes in rainfall seasonality have been found in various tropical regions (Feng et al., 2013) and have been projected for the future climate (Biasutti and Sobel, 2009; Shongwe et al., 2009; Seth et al., 2013), studies investigating their impacts on terrestrial ecosystems are relatively rare, and very few field studies are designed to address this issue (Table 1, Bates et al., 2006; Svejcar et al., 2003). Finally, there is an increasing trend of large-scale studies addressing rainfall variability and ecological responses using satellite remote sensing (Fang et al., 2005; Zhang et al., 2005, 2013; Good and Caylor, 2011; Holmgren et al., 2013) and network flux-tower data (Ross et al., 2012). These large-scale studies are able to expand analyses to more types of ecosystems and different climate conditions, and provide valuable observation-based insights. However, there are very few theoretical modeling works to corroborate this effort. All the above issues call for a comprehensive modeling study to investigate the impact of various intra-seasonal rainfall variabilities on terrestrial ecosystems spanning large environmental gradients and various biomes.

The Africa continent has the world's largest area of arid and semi-arid ecosystems. The fate of these water-limited ecosystems under climate change is critically linked with how rainfall variability changes. In this paper, we aim to answer this overarching question: how do African ecosystems respond to possible changes in intra-seasonal rainfall variability (i.e., rainfall frequency, intensity, and rainy season length)? We design virtual "rainfall manipulation experiments" to concurrently shift intra-seasonal rainfall characteristics without changing total annual rainfall. By doing this, we can exclude the influence from total rainfall amount, and only focus on the impacts of intra-seasonal rainfall variability on terrestrial ecosystems. Particularly, we study the changes of ecosystem productivity (e.g., gross primary production, GPP) and biome distributions in the African continent under different rainfall scenarios, simulated by an independently validated dynamic vegetation model SEIB-DGVM (Sato and Ise, 2012). Previous studies (Gerten et al., 2008; Hély et al., 2006) designed various rainfall scenarios by rearranging (halving, doubling or shifting) the rainfall amount in the existing rainfall observations. As an improvement, we design a new weather generator based on a stochastic rainfall model (Rodríguez-Iturbe et al., 1999), which explicitly incorporates a wet/dry season, and also allows us to synthetically vary two of the three rainfall characteristics (rainfall intensity, rainfall frequency, and rainy season length) while fixing total annual rainfall at the current climatology.

\section{Materials and methods}

\subsection{Methodology overview}

The central idea of our study is to design similar rainfall manipulation experiments as those in the field work (Table 1), but to test them virtually in the model domain across large environment gradients. We manipulate rainfall changes through 

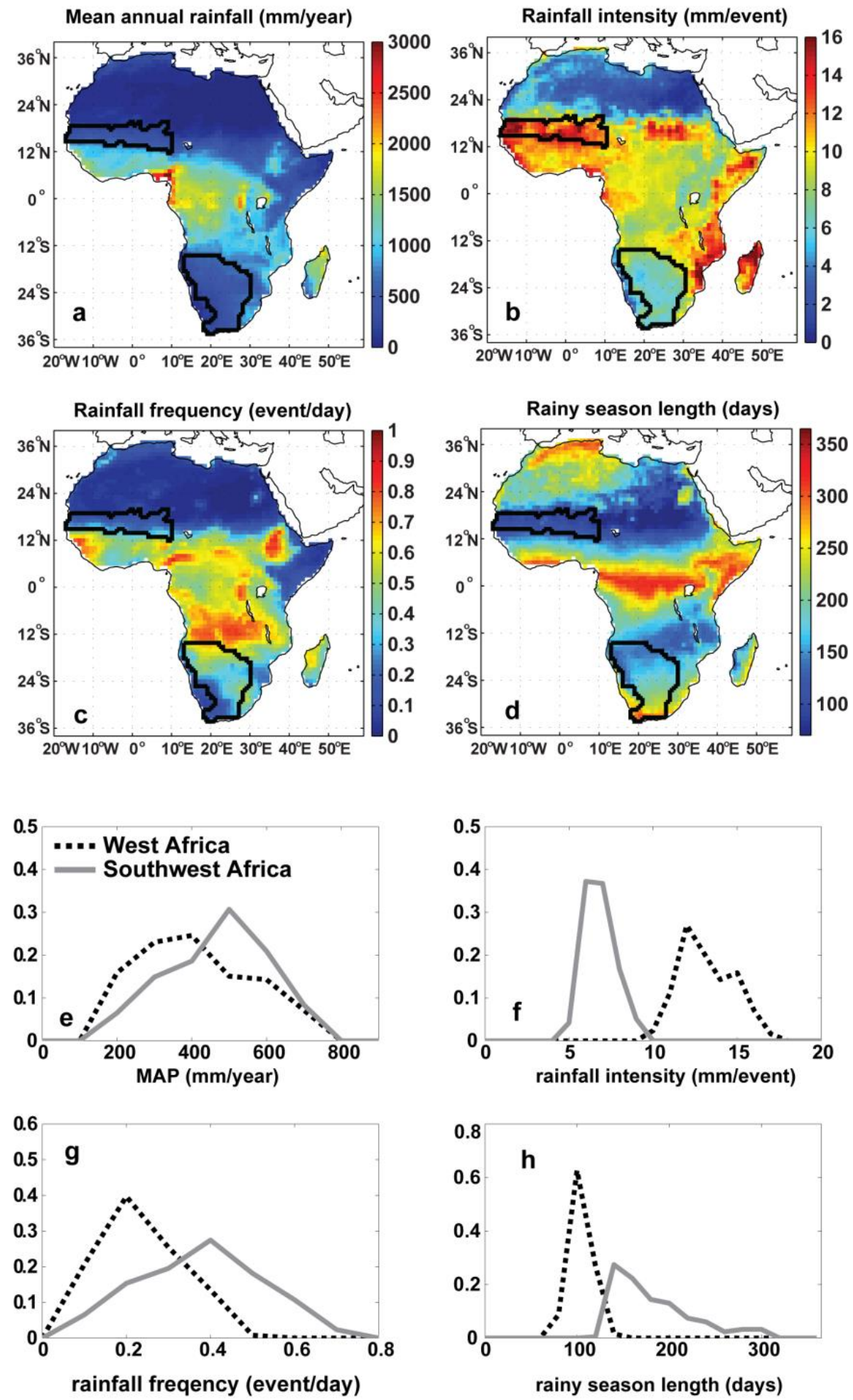

Figure 1. (a-b) Spatial pattern of the rainfall characteristics in Africa: (a) Mean annual precipitation (MAP); (b) rainfall intensity; (c) rainfall frequency; (d) rainy season length. The areas identified by the black line refer to two savanna regions in west and southwest Africa. (e-f) Normalized histograms of the rainfall characteristics in two savanna regions of west and southwest Africa. (e) MAP (bin width for the $x$ axis: $100 \mathrm{~mm} \mathrm{year}^{-1}$ ); (f) rainfall intensity (bin width for the $x$ axis: $1 \mathrm{~mm}^{\text {event }}{ }^{-1}$ ); (g) rainfall frequency (bin width for the $x$ axis: 0.1 event day $^{-1}$ ); (h) rainy season length (bin width for the $x$ axis: 20 days). 
Table 1. Summary of previous representative studies on assessing the impacts of rainfall characteristics (i.e., rainfall frequency, intensity, and seasonality) on the structure and function of terrestrial ecosystem.

\begin{tabular}{|c|c|c|c|c|c|c|c|}
\hline Focus & Methods & Spatial scale & Timescale & MAP (mm year $\left.{ }^{-1}\right)$ & Ecosystem type & Major conclusion & Reference \\
\hline freq; int & RS & African continent & $\begin{array}{l}\text { intra-annual } \\
\text { climatology }\end{array}$ & {$[0,3000]$} & Africa all & (int-) woody cover & $\begin{array}{l}\text { Good and Caylor } \\
\text { (2011) }\end{array}$ \\
\hline freq; int & RS & US & & {$[163,1227]$} & US & $\begin{array}{l}\text { (int-) ANPP greatest in arid grassland (16\%) } \\
\text { and Mediterranean forest }(20 \%) \text { and less for } \\
\text { mesic grassland and temperate forest (3\%) }\end{array}$ & Zhang et al. (2013) \\
\hline freq; int & RS & $\begin{array}{c}\text { Pan-tropics } \\
\left(35^{\circ} \mathrm{N} \text { to } 15^{\circ} \mathrm{S}\right)\end{array}$ & interannual & {$[0,3000]$} & $\begin{array}{c}\text { Tropical } \\
\text { ecosystems }\end{array}$ & $\begin{array}{l}(\mathrm{CV}+) \text { wood cover in dry tropics; } \\
(\mathrm{CV}-) \text { wood cover in wet tropics }\end{array}$ & $\begin{array}{l}\text { Holmgren et al. } \\
\text { (2013) }\end{array}$ \\
\hline freq; int & RS & northern China & intra-annual & {$[100,850]$} & $\begin{array}{l}\text { temperate } \\
\text { grassland } \\
\text { and forests }\end{array}$ & $\begin{array}{l}\text { (int-) NDVI for temperate grassland and } \\
\text { broadleaf forests, not for coniferous forest }\end{array}$ & Fang et al. (2005) \\
\hline freq; int & flux & Northern Hemisphere & intra-annual & $\begin{array}{l}{[393 \pm 155} \\
906 \pm 243]\end{array}$ & $\begin{array}{l}\text { shrubland } \\
\text { and forest }\end{array}$ & (int-) GPP, RE and NEP & Ross et al. (2012) \\
\hline seas & RS & African continent & climatology & {$[0,3000]$} & Africa all & $\begin{array}{l}\text { rainy season onset and offset controls } \\
\text { vegetation growing season }\end{array}$ & Zhang et al. (2005) \\
\hline $\begin{array}{l}\text { freq; int } \\
\text { (fix MAP) }\end{array}$ & field & plot (Kansas, USA) & intra-annual & 615 & grassland & (int-) ANPP & Knapp et al. (2002) \\
\hline $\begin{array}{l}\text { freq; int } \\
\text { (fix MAP) }\end{array}$ & field & plot (Kansas, USA) & intra-annual & 835 & grassland & (int-) ANPP & Fay et al. (2003) \\
\hline $\begin{array}{l}\text { increase } \\
\text { seasonal } \\
\text { rainfall }\end{array}$ & field & plot (Taxes, USA) & intra-annual & 365 & grassland & (int-) ANPP & $\begin{array}{l}\text { Robertson } \\
\text { et al. (2009) }\end{array}$ \\
\hline freq; int & field & plot (Kansas, USA) & intra-annual & {$[320,830]$} & grassland & $\begin{array}{l}\text { (int-)ANPP for MAP=830 } \mathrm{mm} \mathrm{year}^{-1} \text {; } \\
(\mathrm{int}+) \text { ANPP for MAP=320 mm year }\end{array}$ & $\begin{array}{l}\text { Heisler-White } \\
\text { et al. (2009) }\end{array}$ \\
\hline freq; int & field & $\begin{array}{c}\text { plot (New Mexico, } \\
\text { USA) }\end{array}$ & intra-annual & 250 & grassland & (int+) ANPP & $\begin{array}{l}\text { Thomey et al. } \\
\text { (2011) }\end{array}$ \\
\hline $\begin{array}{l}\text { freq; int } \\
\text { (fix MAP) }\end{array}$ & field & plot (Kansas, USA) & intra-annual & 834 & grassland & (int-) soil $\mathrm{CO}_{2}$ flux & Harper et al. (2005) \\
\hline $\begin{array}{l}\text { freq; int } \\
\text { (fix MAP) }\end{array}$ & field & $\begin{array}{l}\text { plot (Kruger National } \\
\text { Park, South Africa) }\end{array}$ & intra-annual & $\begin{array}{c}544 \\
\text { savanna }\end{array}$ & sub-tropical & (int+) wood growth; (int-) grass growth & $\begin{array}{l}\text { Kulmatiski and } \\
\text { Beard (2013) }\end{array}$ \\
\hline $\begin{array}{l}\text { sea } \\
\text { (fix MAP) }\end{array}$ & field & plot (Oregon, USA) & intra-annual & {$[140,530]$} & grassland & impact biomass and bare soil fraction & $\begin{array}{l}\text { Bates et al. (2006), } \\
\text { Svejcar et al. (2003) }\end{array}$ \\
\hline $\begin{array}{l}\text { freq; int; } \\
\text { MAP }\end{array}$ & field & plot (South Africa) & intra-annual & {$[538,798]$} & grassland & (int-) ANPP & $\begin{array}{l}\text { Swemmer et al. } \\
\text { (2007) }\end{array}$ \\
\hline MAP; sea & field & plot (Spain) & $\begin{array}{l}\text { intra-/inter- } \\
\text { annual }\end{array}$ & 242 & grassland & $\begin{array}{l}\text { Mediterranean dryland ecosystem has more } \\
\text { resilience for intra- and interannual changes } \\
\text { in rainfall }\end{array}$ & $\begin{array}{l}\text { Miranda et al. } \\
(2008)\end{array}$ \\
\hline
\end{tabular}

Focus: frequency (freq); intensity (int); seasonality (sea); variation (CV).

Methods: field experiments (field); remote sensing (RS); flux tower (flux).

Major Conclusion: increasing rainfall intensity (or decreasing frequency) has positive impacts (int+); increasing intensity (or decreasing frequency) has negative impacts (int-); increasing rainfall $\mathrm{CV}$ has positive impacts $(\mathrm{CV}+)$; increasing rainfall $\mathrm{CV}$ has negative impacts $(\mathrm{CV}-)$.

Acronyms: ANPP-aboveground net primary production; NDVI-normalized difference vegetation index; GPP-gross primary production; RE-ecosystem respiration;

NEP-net ecosystem production.

a weather generator based on a parsimonious stochastic rainfall model (Rodriguez-Iturbe et al., 1984). We conceptualize the total amount of rainfall during a rainy season as a product of the three intra-seasonal rainfall characteristics: rainfall frequency $\left(\lambda\right.$, event day $\left.{ }^{-1}\right)$, rainfall intensity $\left(\alpha\right.$, mm event $\left.^{-1}\right)$, and rainy season length ( $T_{\mathrm{w}}$, days) (More details in Sect. 2.3). Thus, it is possible to simultaneously perturb two of the rainfall characteristics away from their climatological values while preserving the mean annual precipitation (MAP) unchanged. We then feed these different rainfall scenarios into a well-validated dynamic vegetation model (SEIB-DGVM, Sect. 2) to study simulated ecosystem responses. Detailed experiment design is described in Sect. 2.5.

\subsection{SEIB-DGVM model and its performances in Africa}

We use SEIB-DGVM (Sato et al., 2007) to study ecosystem responses to different rainfall variabilities. This model follows the traditional "gap model" concept (Shugart, 1998) to explicitly simulate the dynamics of ecosystem structure and function for individual plants at a set of virtual vegetation patches, and uses results at these virtual patches as a surrogate to represent large-scale ecosystem states. Thus, individual trees are simulated from establishment, to competition with other plants, to death, which creates "gaps" for other plants to occupy and develop. SEIB-DGVM includes mechanical-based and empirical-based algorithms for 


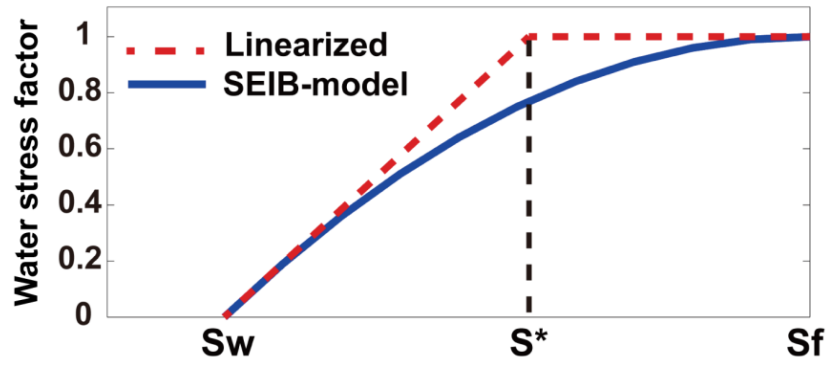

Figure 2. Schematic diagram of water stress factor ranging from 0 (most stressful) to 1 (no stress), which acts to reduce transpiration and carbon assimilation. The red dotted line is based on Porporato et al. (2001) with a reversed sign, and SEIB-DGVM has a nonlinear implementation (blue solid line, Sato and Ise, 2012).

land physical processes, plant physiological processes, and plant dynamic processes. SEIB-DGVM contains algorithms that explicitly involve the mechanisms of plant-related water stress (Fig. 2; Sato and Ise, 2012). With similar concepts to previous studies (e.g., Milly, 1992; Porporato et al., 2001), the current SEIB-DGVM implements a continuous "water stress factor" (Eq. 2) based on the soil moisture status (Eq. 1), scaling from 0 (most stressful) to 1 (with no stress), which then acts to scale the stomatal conductance for plant transpiration and carbon assimilation.

stat $_{\text {water }}=\left(S-S_{\mathrm{w}}\right) /\left(S_{\mathrm{f}}-S_{\mathrm{w}}\right)$

Water stress factor $=2 \times$ stat $_{\text {water }}-$ stat $_{\text {water }}^{2}$

where $S, S_{\mathrm{w}}$, and $S_{\mathrm{f}}$ refer to the fraction of volumetric soil water content within the rooting depth, at the wilting point, and at field capacity, respectively. Figure 2 provides a schematic diagram of water stress factor from the SEIBDGVM, and we also include an approximated linear model that has been widely adopted elsewhere (e.g., Milly, 1992) to help us understand the model performance. The linear model uses an extra variable $S^{*}$, the so-called "critical point" of soil moisture: when $S>S^{*}$, there is no water stress (water stress factor $=1$ ); when $S<S^{*}$, water stress factor linearly decreases with the decrease of $S$. Though SEIB-DGVM adopts a quadratic form for water stress factor, it essentially functions similarly as the linear model, such that $S^{*}$ distinguishes two soil moisture regimes that below which there is a large sensitivity of water stress to soil moisture status, and above which there is little water stress. Understanding how this water stress factor functions is the key to explain the our results.

SEIB-DGVM allows development of annual and perennial grasses as well as multiple life cycles of grass per year based on environmental conditions. Multiple life cycles of tree growth per year are possible in theory but rarely happen in simulations (Sato and Ise, 2012). Soil moisture status is the predominant factor to determine leaf area index (LAI) of the vegetation layer, which influences maximum daily produc- tivity and leaf phenology. When LAI exceeds 0 for 7 continuous days, dormant phase of perennial vegetation layer changes into growth phase. While when LAI falls below 0 for 7 continuous days, growth phase switches to dormant phase (Sato et al., 2007). SEIB-DGVM also explicitly simulates light conditions and light competition among different plant function types (PFTs) in the landscape based on its simulated 3-D canopy structure and radiative transfer scheme (Sato et al., 2007).

SEIB-DGVM has been tested both globally (Sato et al., 2007) and regionally for various ecosystems (Sato et al., 2010; Sato, 2009; Sato and Ise, 2012), and the simulation results compare favorably with ground observations and satellite remote sensing measures for ecosystem composition, structure and function. In particular, SEIB-DGVM has been successfully validated and demonstrated its ability in simulating ecosystem structure and function in the African continent (Sato and Ise, 2012). Two PFTs of tropical woody species are simulated by SEIB-DGVM in Africa: tropical evergreen trees and tropical deciduous trees. The distribution of these two woody types in the simulation is largely determined by hydroclimatic environments. Tropical evergreen trees only develop in regions where water resources are sufficient all year around, so they can maintain leaves for all seasons. If a rainfall regime has clear dry and wet seasons and also has enough rainfall during wet season, tropical deciduous trees develop, and they shed leaves during dry seasons to avoid water stress (Sato and Ise, 2012). Trees and grasses coexist in a cell, with the floor of a virtual forest monopolized by one of the two grass PFTs, $\mathrm{C}_{3}$ or $\mathrm{C}_{4}$ grass. The dominating grass type is determined at the end of each year by air temperature, precipitation, and $\mathrm{CO}_{2}$ partial pressure (Sato and Ise, 2012).

SEIB-DGVM is run at $1^{\circ}$ spatial resolution and at the daily step. We spin up the model for 2000 years driven by the observed climate (1970-2000) repeatedly for the soil carbon pool to reach steady state, followed by 200 years of simulation driven by the forcings based on the experiment design in Sect. 2.4. Since this study focuses on the impacts of intra-seasonal rainfall variability, we turn off the fire component of SEIB-DGVM to exclude fire-mediated feedbacks. Though we are aware that fire may interact with interacting with rainfall seasonality and affect ecosystem productivity and structure (Bond et al., 2005; Lehmann et al., 2011; Staver et al., 2012), studying these interactions is beyond the scope of this work. We also fix the atmospheric $\mathrm{CO}_{2}$ concentration at $380 \mathrm{ppmv}$ to exclude possible impacts of $\mathrm{CO}_{2}$ fertilization effects.

\subsection{Synthetic weather generator}

Our synthetic weather generator has two major components: (i) to generate daily rainfall based on a stochastic rainfall model and (ii) to conditionally sample all other 
environmental variables from historical records to preserve the covariance among climate forcing variables.

The stochastic rainfall model can be expressed as MAP $=$ $\alpha \lambda T_{\mathrm{w}} / f_{\mathrm{w}}$, and we set $f_{\mathrm{w}}$ to be 0.9 , i.e., the period including $90 \%$ of total annual rainfall is defined as "rainy season" (exchangeable with "wet season" hereafter). In particular, we first use the Markham (1970) approach to find the center of the rainy season, and then extend the same length to both sides from the center until the total rainfall amount in this window (i.e., rainy season) is equal to $90 \%$ of the total annual rainfall. Though rainy and dry seasons are separately modeled to have their own rainfall frequency and intensity, here we only manipulate rainy-season rainfall characteristics in our study, as rainy-season rainfall accounts for almost all the meaningful rainfall inputs for plant use. Thus, hereafter when we mention $\alpha$ or $\lambda$, we refer to those for the rainy season.

We use marked Poisson process (Rodríguez-Iturbe et al., 1999) to model rainfall process for a continuous period. Specifically, a rainy day (i.e., daily rainfall amount is more than zero) is counted as one rainy event, and rainfall events occur as a Poisson process, with the parameter $1 / \lambda$ (unit: days/event) being the mean intervals between rainfall events. Rainfall intensity $\alpha$ for each rainfall event follows an exponential distribution, (Rodríguez-Iturbe et al., 1999). The rainy season length is modeled as a beta distribution bounded from 0 to 1 , scaled by 365 days. Based on the above assumptions, we derive all the necessary parameters for the stochastic rainfall model (including the mean and variance of rainfall frequency, intensity, and length of wet and dry seasons) from the satellite-gauge-merged rainfall measurement (1998-2012) from TRMM 3b42V7 (Huffman et al., 2007). Specifically, we first extract the rainy season for each year from the TRMM rainfall data, and calculate the mean and variance of the rainy season length, which we use to fit the beta distribution for $T_{\mathrm{w}}$. Then we lump all the rainy (or dry) season rainfall record together to derive its rainfall frequency and intensity. The synthetic weather generator follows two steps:

Step 1 Model the daily rainfall following the marked Poisson process described above. In particular, for a specific year, we first stochastically generate the wet season length by sampling from the beta distribution, and accordingly determine dry season length. Then we generate the daily rainfall for wet and dry season separately.

Step 2 Based on the simulated daily rainfall time series in Step 1, we conditionally sample temperature, wind, and humidity from the Global Meteorological Forcing Dataset (GMFD, Sheffield et al., 2006), as well as cloud fraction and soil temperature from the Climate Forecast System Reanalysis (CFSR) from National Centers for Environmental Prediction (NCEP) (Saha et al., 2010). To sample for a specific day, we choose from all the historical records that are within a 21-day time window centered at that day. From this sampling pool, we choose the day such that the historical rainfall amount of the chosen day is within $70-130 \%$ of the simulated daily rainfall amount. We then draw all the environmental variables (except rainfall) on that sampled day to the new climate forcing. If we can find a sample from the pool based on the above rule, this sampling is called "successful". When there is more than one suitable sample, we randomly select one. When there is no suitable sample, we randomly select one day within the pool. The mean successful rate for all the experiments and ensembles across Africa is $83 \%$.

To test the validity of the synthetic weather generator, we run SEIB-DGVM using the historical climate record $\left(S_{\text {climatology }}\right)$ and the synthetic forcing $\left(S_{\text {control }}\right)$, with the latter generated using the weather generator based on the rainfall characteristics derived from the former. Supplement Fig. S1 shows that the SEIB-DGVM simulations driven by these two different forcings generate similar biome distributions with a Cohen's kappa coefficient of 0.78 (Cohen, 1960), and similar GPP patterns in Africa, with the linear fit of annual GPP as $\operatorname{GPP}\left(S_{\text {control }}\right)=1.03 \times \operatorname{GPP}\left(S_{\text {climatology }}\right)+0.215$ $\left(R^{2}=0.89, P<0.0001\right.$, Fig. S2). The simulated biome and GPP patterns are consistent with observations (Sato and Ise, 2012). These results provide confidence in using the synthetic weather generator and SEIB-DGVM to conduct the further study.

\subsection{Experiment design and analysis}

Three experiments are designed as follows:

Experiment $S_{\lambda-\alpha}$ : Simulations forced by the synthetic forcings with varying $\lambda$ and $\alpha$ simultaneously for wet season (20\% increases of $\lambda$ and corresponding decreases of $\alpha$ to make MAP unchanged; $20 \%$ decreases of $\lambda$ and corresponding increases of $\alpha$ to make MAP unchanged; no change for dry season rainfall characteristics), while fixing $T_{\mathrm{w}}$ at the current climatology;

Experiment $S_{T \mathrm{w}-\lambda}$ : Simulations forced by the synthetic forcing with varying $T_{\mathrm{w}}$ and $\lambda$ simultaneously for wet season (20\% increases of $T_{\mathrm{w}}$ and corresponding decreases of $\lambda$ to make MAP unchanged; $20 \%$ decreases of $T_{\mathrm{w}}$ and corresponding increases of $\lambda$ to make MAP unchanged; no change for dry season characteristics), while fixing $\alpha$ at the current climatology;

Experiment $S_{T \mathrm{w}-\alpha}$ : Simulations forced by the synthetic forcing with varying $T_{\mathrm{w}}$ and $\alpha$ simultaneously for wet season (20\% increases of $T_{\mathrm{w}}$ and corresponding decreases of $\alpha$ to make MAP unchanged; $20 \%$ decreases of $T_{\mathrm{w}}$ and corresponding increases of $\alpha$ to make MAP unchanged; no change for dry season characteristics), while fixing $\lambda$ at the current climatology.

Because $\lambda$ and $T_{\mathrm{w}}$ have bounded ranges $(\lambda \sim[0,1]$ and $\left.T_{\mathrm{w}} \sim[0,365]\right)$, if these two variables after perturbation exceed the range, we would force their value to be the lower or upper bound, and rearrange the other corresponding rainfall characteristic to ensure MAP unchanged. Each rainfall scenario has six ensemble realizations of synthetic 
climate forcings to account for the stochasticity of our synthetic weather generator.

For each experiment, we analyze the differences in simulated biome distributions, annually averaged soil moisture, and GPP between the two scenarios in each experiment (i.e., $\left.S_{\lambda-\alpha}, S_{T_{\mathrm{w}-\lambda}}, S_{T_{\mathrm{w}-\alpha}}\right)$. These differences represent the simulated ecosystem sensitivity to the slight perturbation of intraseasonal rainfall characteristics deviating from the current climatology with no change in MAP. To further explore how these rainfall characteristics affect the simulated GPP across a wide range of MAP, we analyze the difference of simulated GPP as a function of MAP and one of the perturbed rainfall characteristics in each experiment (Fig. 5), which is termed as "GPP sensitivity space". Positive GPP sensitivity means that GPP changes in the same direction with MAP or rainfall characteristics, and vise versa for negative "GPP response". These GPP sensitivity spaces are generated based on the aggregated GPP difference in each bin of the rainfall properties. The bin size for MAP, rainfall frequency, rainfall intensity, and rainy season length are $100 \mathrm{~mm}$ year $^{-1}, 0.05$ event day ${ }^{-1}, 1 \mathrm{~mm}^{2}$ event $^{-1}$, and 15 days, respectively. We also provide the standard error (SE) of the GPP sensitivity spaces in each bin to assess their uncertainties, with higher SE meaning larger uncertainties. $\mathrm{SE}=\sigma / \sqrt{n}$, where $\sigma$ and $n$ refer to the standard deviation and the sample size in each bin, respectively. A series of illustrations in Fig. 6 are generalized from the simulated time series, and they are used here to explain the underlying mechanisms.

\section{Results}

\subsection{Ecosystem sensitivity to rainfall frequency and intensity (Experiment $S_{\lambda-\alpha}$ )}

Experiment $S_{\lambda-\alpha}$ assesses ecosystem responses to the change of increased rainfall frequency and decreased rainfall intensity (i.e., $\lambda \uparrow, \alpha \downarrow$ ) under a fixed total annual rainfall. The simulated biome distributions show that a small portion of woodlands ( $3 \%$ area of woodlands) are converted to grasslands at low rainfall regime $\left(\sim 500 \mathrm{~mm} \mathrm{year}^{-1}\right)$, corresponding to a decrease of GPP in these regions. In the high rainfall regime (around $1500 \mathrm{~mm}_{\text {year }}{ }^{-1}$, Fig. 3a), increased rainfall frequency significantly converts tropical evergreen forests (18\% of their area) to woodlands. In the intermediate rainfall regime $\left(600-1000 \mathrm{~mm}_{\text {year }}{ }^{-1}\right)$, there is little change in biome distribution. Spatially (Fig. 4a), GPP increases with increased rainfall frequency across most of the Africa continent, except in the very dry end (in southern and eastern Africa) and the very wet regions (in central Africa and northeastern Madagascar). This GPP pattern mostly mirrors the soil moisture change in woodlands and grasslands (Fig. 4b), except that the wet tropics show a reversed change of soil moisture and GPP.
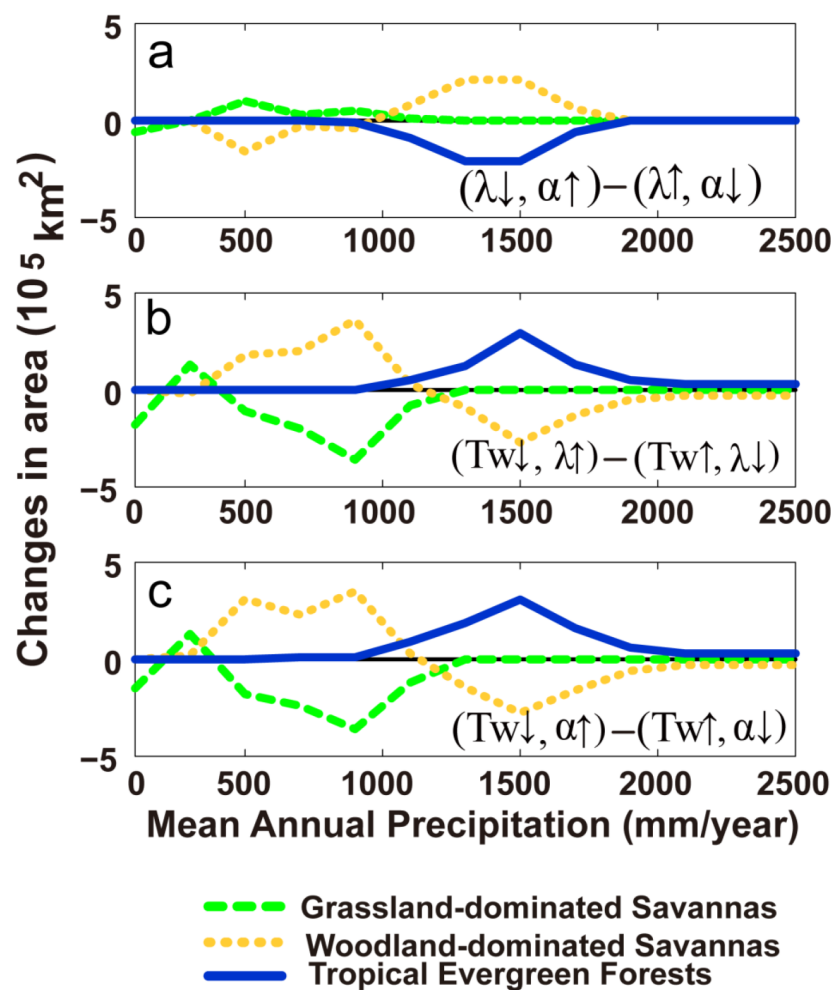

Figure 3. Differences in simulated dominated biomes in the three experiments (i.e., $S_{\lambda-\alpha}, S_{T_{\mathrm{w}-\lambda}}, S_{T_{\mathrm{w}-\alpha}}$ ).

Figure 5a shows the GPP sensitivity as a function of MAP and the climatological rainfall frequency, and we find three major patterns:

Pattern 1.1 Negative GPP sensitivity shows up in the very dry end of MAP regime (MAP $<400 \mathrm{~mm}^{2} \mathrm{yer}^{-1}$ ) and with relatively low rainfall frequency $\left(\lambda<0.3\right.$ event day $\left.{ }^{-1}\right)$, i.e., GPP decreases with more frequent but less intense rainfall in this low rainfall range.

Pattern 1.2 Across most rainfall ranges (MAP from $400 \mathrm{~mm}_{\text {year }}{ }^{-1}$ to $1600 \mathrm{~mm}$ year $^{-1}$ ), increased frequency of rainfall (and simultaneously decreased rainfall intensity) leads to positive GPP sensitivity. This positive GPP sensitivity peaks at the low range of rainfall frequency $(\sim 0.35$ event day $^{-1}$ ) and around the MAP of 1000 mm year $^{-1}$.

Pattern 1.3 At the high range of MAP $\left(>1800 \mathrm{mmyear}^{-1}\right)$ with low rainfall frequency $(\sim 0.4$ event $\mathrm{day}^{-1}$ ), GPP decreases with increased rainfall frequency.

The GPP sensitivity with respect to MAP and rainfall intensity (Fig. 5c) shows an unclear pattern and also contains relatively large uncertainties (Fig. 5d). These large uncertainties arise mostly because the rainfall intensity in all the simulated regions cluster in a relatively narrow range (Supplement Fig. S5c), and meanwhile the simulated GPP sensitivity for these regions also have large variance (Fig. S5d). Thus, we will not over-interpret the pattern in Fig. 5c. 

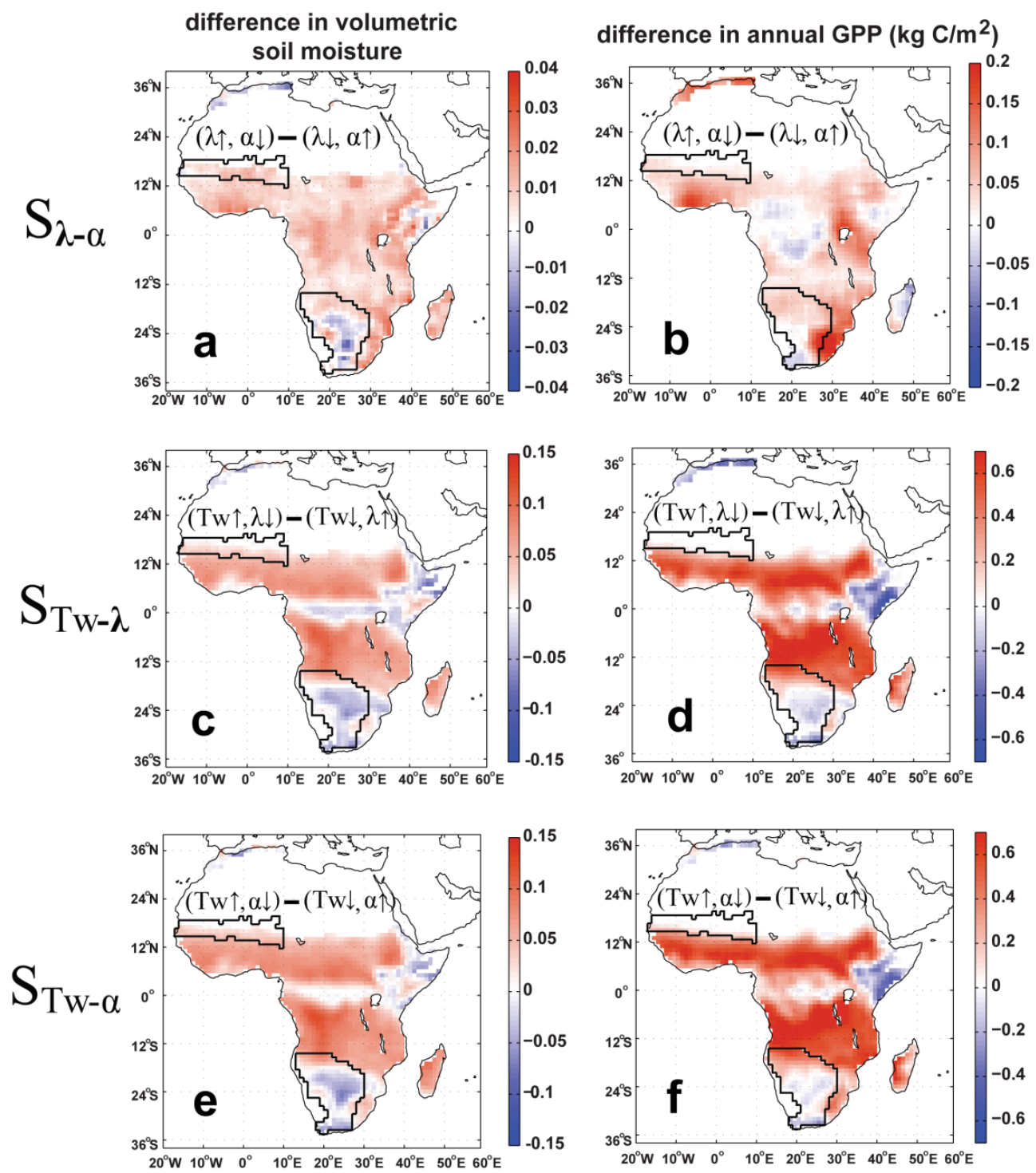

Figure 4. Simulated changes in annual mean soil moisture (0-500 mm, first column) and annual mean GPP (second column) for different experiments. Please note that the scales of $S_{\lambda-\alpha}$ are much smaller than those of $S_{T_{\mathrm{w}-\lambda}}$ and $S_{T_{\mathrm{w}-\alpha}}$. The two areas with black boundaries in each panel are west African grasslands and southwest African grasslands associated with Fig. 1. The spatial patterns shown here are smoothed by a $3 \times 3$ smoothing window from the raw output.

Pattern 1.1 and Pattern 1.2 can be explained by the illustrative time series in Fig. 6a and b, respectively. When rainfall events are small and very infrequent (Fig. 6a), increasing rainfall frequency while decreasing intensity would cause less rainfall penetration to the deeper soil layer, and lead to more evaporation from shallow soil moisture. Thus root-zone soil moisture would drop below the wilting point $S_{\mathrm{w}}$ more frequently (so called "downcrossing"), which subsequently would reduce the effective time of carbon assimilation and plant growth. This case only happens where MAP is very low with low frequency and the biome is predominantly grasslands, which explains the spatial distribution of negative changes in soil moisture and GPP (Fig. 4a and b). This result also corroborates the field findings (Heisler-White et al., 2009; Thomey et al. 2011) of the negative impacts from increased rainfall frequency at low rainfall regimes.

The positive sensitivity of soil moisture and GPP with increased rainfall frequency (Pattern 1.2) is explained in Fig. 6b. Once rainfall events are more frequent and/or more intense than the last case, downcrossings of $S_{\mathrm{w}}$ do not easily happen. Instead, accumulative rainy-season soil moisture becomes the dominant control of plant growth, and increasing rainfall frequency leads to a significant increase of soil moisture for plant water use (Fig. 4a and b). This conclusion drawn from our numerical modeling is consistent with previous findings in Rodríguez-Iturbe and Porporato (2004) 

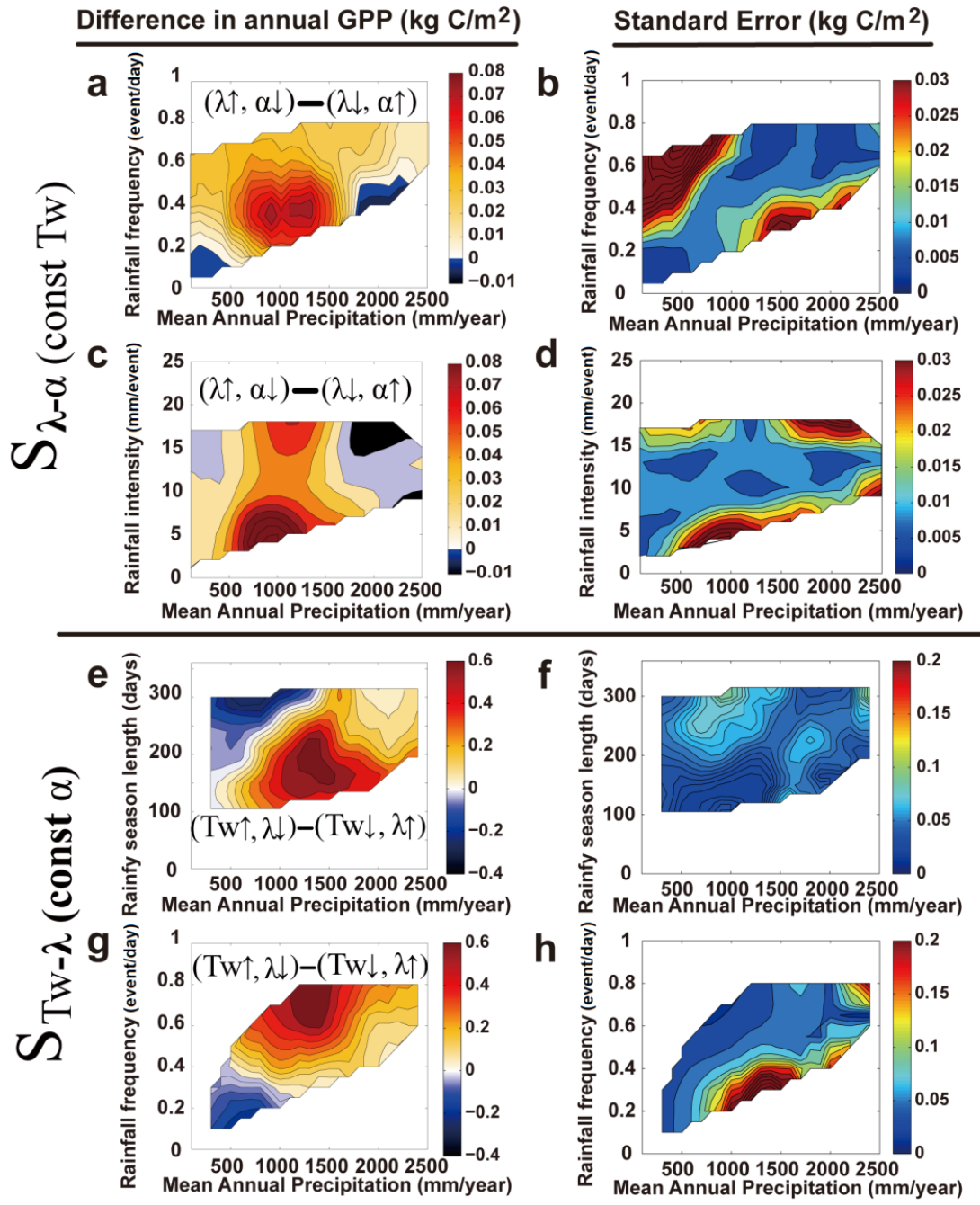

h
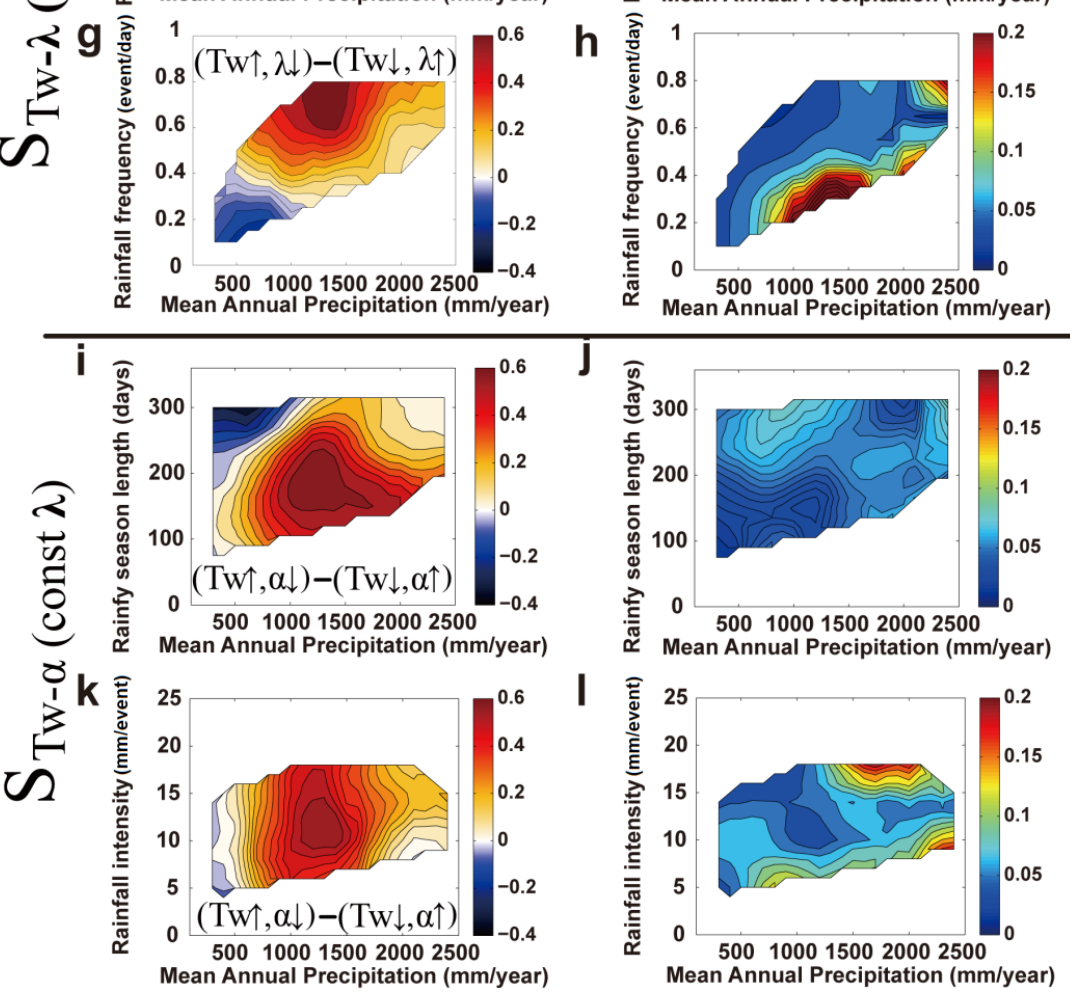

Figure 5. (Left column) Differences in simulated annual GPP as a function of mean annual precipitation and one of the perturbed rainfall characteristics in all the three experiments (i.e., $S_{\lambda-\alpha}, S_{T_{\mathrm{w}-\lambda}}, S_{T_{\mathrm{w}-\alpha}}$ ). (Right column) The correspondent standard errors (SE, calculated as $\mathrm{SE}=\sigma / \sqrt{n}$, where $\sigma$ refers to the standard deviation within each bin, $n$ is the sample size in each bin, and $n$ and $\sigma$ are shown in Fig. S5). Large values of SE means that the corresponding area on the left column contains more uncertainties and requires more caution in interpretation. The contours are based on the binned values, with for each $100 \mathrm{~mm}^{-1} \mathrm{ear}^{-1}$ in MAP, each 0.05 event day ${ }^{-1}$ in rainfall frequency, each $1 \mathrm{~mm}^{-1} \mathrm{eve}^{-1}$ in rainfall intensity, and each 15 days in rainy season length. 


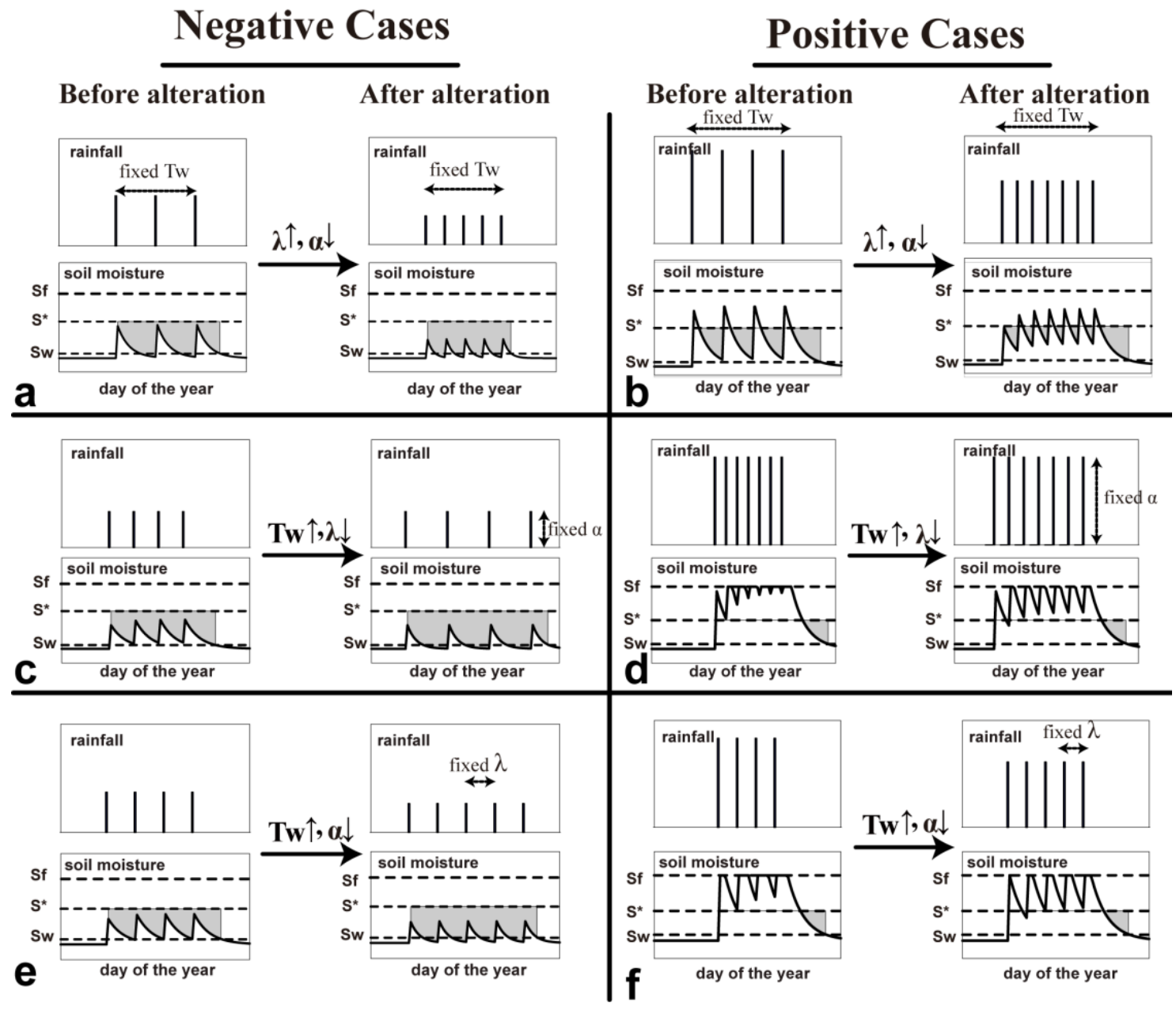

Figure 6. Illustrative time series for hydrological controls on plant root-zone soil moisture dynamics for all the experiments, and these illustrations are generalized based on the simulated time series from the experiment. Both negative and positive cases caused by direct hydrological mechanisms are shown, and cloud-induced negative impacts in tropical forests are not shown.

based on stochastic modeling. We also find that this positive GPP sensitivity reaches its maximum in the intermediate total rainfall $\left(\sim 1000 \mathrm{~mm}\right.$ year $\left.^{-1}\right)$ and relatively low rainfall frequency $\left(\sim 0.35\right.$ event day $\left.{ }^{-1}\right)$, indicating that in these regimes increasing rainfall frequency could most effectively increase soil moisture for plant water use and create marginal benefits of GPP to the increased rainfall frequency. Further increasing total annual rainfall or rainfall frequency would reduce the vegetation sensitivity to water stress by fewer downcrossings of soil moisture critical point $S^{*}$; once the soil moisture is always ample (i.e., above $S^{*}$ ), the changes in either MAP or rainfall frequency would not alter plant water stress.

Pattern 1.3 also shows a negative GPP sensitivity, but its mechanism is different from Pattern 1.1. When total annual rainfall is more than $1800 \mathrm{~mm}_{\text {year }}{ }^{-1}$, SEIB-simulated tropical forests have little water limitation, but instead exhibit radiation limitation. Increase of rainfall frequency at daily scale would enhance cloud fraction and suppress plant productivity in these regions (Graham et al., 2003). Thus, though soil moisture still increases (Fig. 4a), GPP decreases with increased rainfall frequency. This mechanism also explains why tropical evergreen forests shrink in area with increased rainfall frequency (Fig. 3a).

It is worth noting that the magnitude of GPP changes due to rainfall frequency and intensity is small in most woodlands, and is relatively more important for drylands with MAP below $600 \mathrm{~mm}_{\text {year }}{ }^{-1}$ (up to $10-20 \%$ of annual GPP). This relatively small GPP change has translated into a modest change in biome distribution between woodlands and grasslands in $S_{\lambda-\alpha}$ (Fig. 3a).

\subsection{Ecosystem sensitivity to rainfall seasonality and fre- quency (Experiment $S_{T_{\mathrm{w}-\lambda}}$ )}

Experiment $S_{T_{\mathrm{w}-\lambda}}$ assesses ecosystem responses to the change of increased rainy season length and 
decreased rainfall frequency (i.e., $T_{\mathrm{w}} \uparrow, \lambda \downarrow$ ) under a fixed total annual rainfall. We find a gain in areas of tropical evergreen forests ( $16 \%$ of their area) converted from woodlands. Northern Africa has an increase of woodlands (10\% area of woodlands) converted from grasslands, and the Horn of Africa has a small expansion of grasslands into woodlands (Fig. 3b). Figure $4 c$ and $4 d$ show that increasing rainy season length and decreasing frequency would significantly increase annual mean soil moisture and GPP (up to $30 \%$ ) in woodlands. Meanwhile, soil moisture and GPP decrease in southern and eastern Africa. Tropical evergreen forests show little response. We further explore the GPP sensitivity space (Fig. 5e and g), and find the following robust patterns (based on small standard errors shown in Fig. $5 f$ and $h$ ):

Pattern 2.1: The negative GPP sensitivity tends to happen where MAP is below $1000 \mathrm{~mm}_{\text {year }}{ }^{-1}$ with long rainy season length $\left(T_{\mathrm{w}}>150\right.$ days) and low rainfall frequency $(\lambda<0.35$ event day $\left.{ }^{-1}\right)$.

Pattern 2.2: When MAP and rainfall frequency are large enough (MAP $>1000 \mathrm{~mm} \mathrm{year}^{-1}$ and $\lambda>0.4$ event day $^{-1}$ ), decreasing $\lambda$ while increasing $T_{\mathrm{w}}$ would significantly increase GPP. The maximum positive GPP sensitivity happens at the intermediate MAP range (1100-1500 $\left.\mathrm{mm} \mathrm{year}^{-1}\right)$ and high rainfall frequency $\left(\lambda \sim 0.7\right.$ event day $\left.{ }^{-1}\right)$.

Pattern 2.3: There exists an "optimal rainy season length" for relative GPP changes in ecosystem productivity across large MAP ranges (the white area between the red and blue space in Fig. 5e). For the same MAP, any deviation of $T_{\mathrm{w}}$ from the optimal rainy season length would reduce GPP. This optimal rainy season length follows an increasing trend with MAP up to $1400 \mathrm{~mm}_{\text {year }}{ }^{-1}$.

The negative GPP sensitivity in Pattern 2.1 is explained in Fig. $6 \mathrm{c}$. In the situation with low MAP and infrequent rainfall events, decreasing rainfall frequency and expanding rainy season length (i.e., $T_{\mathrm{w}} \uparrow, \lambda \downarrow$ ) would lead to longer intervals between rainfall events and possibly longer excursions below $S_{\mathrm{w}}$, which would disrupt continuous plant growth and have detrimental effects on ecosystem productivity. It is worth noting that a long rainy season in drylands (Fig. 5e) is usually accompanied with low rainfall frequency (Fig. 5g). Southern African drylands (south of $15^{\circ} \mathrm{S}$ ) are in this category, and they thus show negative GPP sensitivity (Fig. $4 \mathrm{c}$ and d), accompanied by a small biome conversion from woodlands to grasslands (Fig. 3b).

The positive GPP sensitivity in Pattern 2.2 is explained in Fig. 6d. When rainfall is ample during rainy season, increasing the interval of rainfall events may bring little benefit for plant growth, but extending the rainy season can significantly increase plant productivity and even increase tree fraction cover. This situation mostly happens in woodlands, where they have limited water stress during rainy season, and their growth is mainly constrained by dry season length. Thus, the increase of rainy season length extends the temporal niche for plant growth, and leads to a significant woodland expansion to grasslands as well as an expansion of tropical evergreen forests to woodlands (Fig. 3b).

Tropical evergreen forests show little GPP sensitivity (Fig. 4d). This is because that these ecosystems already have a long rainy season, and further increasing $T_{\mathrm{w}}$ may reach its saturation (365 days) and has little impact to ecosystem productivity. This also explains why the magnitude of GPP sensitivity is much smaller at high MAP range than at the intermediate MAP range.

With a given total annual rainfall, optimal rainy season length essentially defines how long of a rainy season would optimally benefit vegetation growth. Both water budget partitioning (e.g., runoff, soil evaporation, and plant transpiration) and vegetation dynamics (e.g., tree/grass composition) contribute to this result. For example, too short a rainy season would not support tree growth, while too long a rainy season may lead to too much soil evaporation. This model-based result (Fig. 5e) is consistent with our previous empirical finding about the similar pattern of optimal rainy season length for tree fractional cover in Africa based on satellite remote sensing (Guan et al., 2014). These results fully demonstrate the importance of explicitly considering the nonlinear impacts of rainy season length on ecosystem productivity under climate change, which has been largely overlooked before.

\subsection{Ecosystem sensitivity to rainfall seasonality and intensity $\left(S_{T_{\mathrm{w}-\alpha}}\right)$}

Experiment $S_{T_{\mathrm{w}-\alpha}}$ yields similar results as $S_{T_{\mathrm{w}-\lambda}}$, including the similar changes in biome distributions (Fig. 3), soil moisture (Fig. 4e), and GPP patterns (Fig. 4f). The GPP sensitivity space with MAP and rainy season length for $S_{T_{\mathrm{W}-\alpha}}$ (Fig. 5i) is also similar to that for $S_{T_{\mathrm{w}-\lambda}}$ (Fig. 5e). One new finding is that rainfall intensity has little impact on GPP sensitivity across the large MAP range as the contour lines in Fig. 5k are mostly parallel with the $y$ axis (i.e., rainfall intensity).

Figure 6e and $\mathrm{f}$ explain the governing hydrological mechanisms for the results of $S_{T_{\mathrm{w}-\alpha}}$, which also have many similarities with $S_{T_{\mathrm{w}-\lambda}}$. For the negative case (Fig. 6e), decreasing rainfall intensity and increasing rainy season length in the very low MAP regime can lead to more downcrossings of $S_{\mathrm{w}}$ and interrupt continuous plant growth. The positive case (Fig. 6e) is similar to that in Fig. 6d, i.e., the repartitioning of excessive wet-season rainfall to the dry season for an extended growing period would significantly benefit plant growth and possibly increase tree fraction cover.

\section{Discussion}

\subsection{Limitation of the methodology}

Though our modeling framework is able to characterize the diverse ecosystem responses to the shifts in different rainfall characteristics, it nevertheless has its limitations. The current rainfall model only deals with the case of single rainy season 
per year and approximates the case of double rainy seasons per year to be the single rainy season case. This assumption may induce unrealistic synthetic rainfall patterns in the equatorial dryland regions, in particular the Horn of Africa, possibly yielding less reliable results. However, since most of the African continent has a single rainy season (Guan et al., 2013), our results should be robust at such a large scale. We assume that rainfall frequency and intensity are homogenous throughout wet seasons (or dry seasons), but in reality they have seasonal variations (e.g., phase and varying magnitude). This limitation can be possibly overcome by simulating smaller intervals of rainfall processes (e.g., each month has their own $\alpha$ and $\lambda$ ) rather than simulating the whole wet or dry season using one fixed set of $\alpha$ and $\lambda$. However, we argue that these methodology limitations do not change the qualitative results presented here. First, our weather generator has good performance when compared with the actual climate observation (Figs. S1 and S2), with an almost constant bias in simulated GPP (i.e., interceptions in Fig. S2); besides, the dynamic phenology schemes in SEIB, as well as using the relative change of GPP (through normalizing with the baseline simulated GPP), have further reduced the possible errors of the absolute values of simulated GPP. Furthermore, our approach is an improvement by explicitly including the rainy season length to the original marked Poisson process-based rainfall model (Rodríguez-Iturbe et al., 1984). We thus believe that our study's novelty is evident, and our results are robust and reliable at the continental scale.

Only using one ecosystem model here means that the simulated ecosystem sensitivity can be model-specific. Though magnitudes or thresholds for the corresponding patterns may vary depending on different models, we argue that the qualitative results for the GPP sensitivity patterns (e.g., Fig. 4 and Fig. 5) should hold as the necessary ecohydrological processes have been incorporated in SEIB-DGVM. We also recognize that to exclude fire impacts in the current simulation may bring some limitations for this study, as many savanna regions can be bistable due to fire effects (Staver et al., 2011; Hirota et al., 2011; Higgins and Scheiter, 2012; also, for a possible rebuttal, see Hanan et al., 2013). Changes in rainfall regimes not only affect vegetation productivity directly, but can also indirectly influence ecosystems through interactions with fire, possibly leading to rapid biome shifts. These feedbacks can be important when the changes in rainy season length are related to fuel loads, fuel moisture dynamics, and hence fire intensity (Lehmann et al., 2011). Quantifying these fire-rainfall feedbacks could be an important task for the future.

\subsection{Clarifying the impacts of rainfall frequency and intensity on ecosystem productivity}

In this modeling study, we provide a potential answer for resolving the ongoing decreasing rainfall frequency, i.e., $\lambda \downarrow, \alpha \uparrow)$ has positive or negative impacts on above- ground primary productivity under a fixed annual rainfall total. We identify that negative GPP sensitivity with increased rainfall frequency happens at a very low MAP range $\left(\sim 400 \mathrm{~mm} \mathrm{year}^{-1}\right)$ with relatively low rainfall frequency $\left(<0.35\right.$ event day $\left.^{-1}\right)$ (Fig. 5a) due to increased downcrossings of soil moisture wilting point, which restricts plant growth (Fig. 6a). This derived MAP threshold $\left(\sim 400 \mathrm{~mm}\right.$ year $\left.^{-1}\right)$ is consistent with our meta-analysis of previous field studies (Table 1), which shows that a threshold of MAP at $340 \mathrm{~mm}_{\text {year }}{ }^{-1}$ separates positive and negative impacts of more intense rainfall on aboveground net primary production (ANPP). Our findings are also consistent with another study about increased tree encroachments with increased rainfall intensity in a low rainfall regime $\left(<544 \mathrm{~mm}\right.$ year $^{-1}$, Kulmatiski and Beard, 2013), which essentially follows the same mechanism as identified in Fig. 6a.

In addition, we thoroughly investigate the ecosystem responses across a wide range of annual rainfalls in Africa. We find that beyond the very low rainfall range (below $400 \mathrm{~mm}$ year $^{-1}$ ), most grasslands and woodlands would benefit from increased rainfall frequency, which also corroborate the previous finding that higher rainfall frequency (and lower rainfall intensity) increases tree fraction cover across the African continent (Good and Caylor, 2011). The only exception happens at the very wet end of MAP $\left(\sim 1800 \mathrm{~mm}\right.$ year $\left.^{-1}\right)$, where cloud-induced radiationlimitation with increased rainfall frequency may suppress ecosystem productivity. We also find that changes in rainfall frequency and intensity mostly affect grassland-dominated savannas (changes of GPP up to 20\%), but have much smaller effects for woodland productivity and distribution. In summary, our work provides a primary assessment for the impact of interactive changes between rainfall frequency and intensity in ecosystem function and structure; compared with previous studies (e.g., Porporato et al., 2004), this study expands the analysis to a much wider range of annual rainfall conditions.

\subsection{Ecological importance of rainy season length}

Our results involving rainy season length (i.e., $S_{T_{\mathrm{w}-\lambda}}$ and $S_{T_{\mathrm{w}-\alpha}}$ ) fully demonstrate the ecological importance of rainfall seasonality. The magnitudes of changes in GPP in $S_{T_{\mathrm{w}-\lambda}}$ and $S_{T_{\mathrm{w}-\alpha}}$ are much larger than those of $S_{\lambda-\alpha}$, with almost 1 order of magnitude difference. These disproportional impacts of rainy season length indicate that slight changes in rainy season length could modify biome distribution and ecosystem function more dramatically compared with the same percentage of change in rainfall frequency and intensity. We also notice that $S_{T_{\mathrm{w}-\lambda}}$ and $S_{T_{\mathrm{w}-\alpha}}$ have similar results. This is because both $\lambda$ and $\alpha$ describe rainfall characteristics within the wet season, while $T_{\mathrm{w}}$ describes rainfall characteristics of both dry season and wet season. By explicitly simulating wet and dry season in our synthetic rainfall model, combined with a vegetation dynamic model, we are able to 
quantify the critical role of rainy season length for terrestrial ecosystems.

Given the importance of rainy season length, its ecological impacts under climate change are largely understudied, though substantial shifts in rainfall seasonality have been projected in both the Sahel and South Africa (Biasutti and Sobel, 2009; Shongwe et al., 2009; Seth et al., 2013). The climate community has focused on specific aspects of rainfall, e.g., changes in seasonal rainfall total (Stocker et al., 2013) and increase of extreme rainfall events (Field et al., 2012), and the latter could be captured by the changes in $\lambda$ or $\alpha$ towards heavier tails in their distribution. However, explicit and systematic assessments and projections on rainfall seasonality changes (including both phase and magnitude) are still limited even in the latest Intergovernmental Panel on Climate Change (IPCC) synthesis reports (Field et al., 2012; Stocker et al., 2013). More detailed studies related to these changes and their ecological implications are required for future hydroclimate-ecosystem research.

\subsection{Not all raindrops are ecologically the same}

As Fig. 1 gives a convincing example that the same total annual rainfall may arrive in a very different way, our results further demonstrate that ecosystems respond differently to the changes in these intra-seasonal rainfall variability. For example, with similar MAP, drylands in west Africa and southwest Africa show reversed responses to the same changes in intra-seasonal rainfall variability. As shown in the experiments of $S_{T_{\mathrm{w}-\lambda}}$ and $S_{T_{\mathrm{w}-\alpha}}$, increasing $T_{\mathrm{w}}$ while decreasing $\lambda$ or $\alpha$ generates slightly positive GPP sensitivity in west Africa (Fig. 4c and d), but causes a relatively large GPP decrease in southwest Africa. The prior hydroclimate conditions of these two regions largely explain these differences: west Africa has much shorter rainy season with more intense rainfall events; while southwest Africa has a long rainy season but many small and sporadic rainfall events. As a result, under a fixed annual rainfall total, slightly increasing the rainy season while decreasing rainfall intensity would benefit plant growth in west Africa, but the same change in southwest Africa would lengthen dry spells and reduce its ecosystem productivity. We further deduce that the rainfall use efficiency (RUE, defined as the ratio of plant net primary production to total rainfall amount) in these two drylands could be different: west Africa could have lower RUE, and the intense rainfall could lead to more infiltration-excess runoff, and thus less water would be used by plants; while southwest Africa can have higher RUE because its sporadic and small rainfall events would allow grass to fully take advantage of the ephemerally existing water resources. This conclusion is partly supported by Martiny et al. (2007), based on satellite remote sensing. We further hypothesize that landscape geomorphology in these two drylands may be different and therefore reflect distinctive rainfall characteristics. More bare soil would exist in west Africa grasslands due to erosion in- duced by intense rainfall, while southwest Africa would have more grass fraction and less bare soil fraction. Testing these interesting hypotheses is beyond the scope of this paper, but is worth further exploration.

\section{Conclusions}

In summary, we provide a new modeling approach to systematically study the ecological impacts from changes in intra-seasonal rainfall characteristics (i.e., rainfall frequency, rainfall intensity, and rainy season length) across various biomes and large climate gradients in the African continent. Our proposed framework (synthetic weather generator, experiment design, and vegetation dynamic modeling) allows the explicit consideration of wet and dry season, excludes the effects from the total rainfall amount and only focuses on the intra-seasonal rainfall variability. Our results provide a possible answer to resolve the debates related to impacts of rainy season frequency/intensity on dryland productivity. We also demonstrate the overlooked importance of rainy season length on ecosystem functions and structure, which has much larger impacts than the same percentage change of rainfall frequency and intensity, especially for tropical woodlands. Our study suggests that the climate change community should provide more assessments on changes in rainfall seasonality, and that intra-seasonal rainfall characteristics should be explicitly considered in future ecosystem studies.

\section{The Supplement related to this article is available online at doi:10.5194/bg-11-6939-2014-supplement.}

Acknowledgements. K. Guan and E. F. Wood acknowledge the financial support of the NASA NESSF fellowship. S. P. Good and K. K. Caylor acknowledge the financial support of the National Science Foundation through grant EAR-0847368. We thank Ignacio Rodríguez-Iturbe for his valuable input and discussion. We also thank the editor Chris Williams and two anonymous reviewers for providing constructive suggestions to improve the overall quality of the work.

Edited by: C. A. Williams 


\section{References}

Allan, R. and Soden, B.: Atmospheric warming and the amplification of precipitation extremes, Science, 1481-1485, 2008.

Anderegg, L. D. L., Anderegg, W. R. L., and Berry, J. A.: Not all droughts are created equal: translating meteorological drought into woody plant mortality, Tree Physiol., 33, 701-712, 2013.

Bates, J., Svejcar, T., Miller, R., and Angell, R.: The effects of precipitation timing on sagebrush steppe vegetation, J. Arid Environ., 64, 670-697, 2006.

Biasutti, M. and Sobel, A. H.: Delayed Sahel rainfall and global seasonal cycle in a warmer climate, Geophys. Res. Lett., 36, L23707, doi:10.1029/2009GL041303, 2009.

Bond, W. J., Woodward, F. I., and Midgley, G. F.: The Global Distribution of Ecosystems in a World without Fire, New Phytol., $165,525-537,2005$.

Chou, C., Chiang, J. C. H., Lan, C.-W., Chung, C.-H., Liao, Y.-C., and Lee, C.-J.: Increase in the range between wet and dry season precipitation, Nat. Geosci., 6, 263-267, 2013.

Easterling, D. R., Meehl, G. A., Parmesan, C., Changnon, S. A., Karl, T. R., and Mearns, L. O.: Climate Extremes: Observations, Modeling, and Impacts, Science, 289, 2068-2074, 2000.

Fang, J., Piao, S., Zhou, L., He, J., Wei, F., Myneni, R. B., Tucker, C. J., and Tan, K.: Precipitation patterns alter growth of temperate vegetation, Geophysi. Res. Lett., 32, L21411, doi:10.1029/2005GL024231, 2005.

Fay, P. A., Carlisle, J. D., Knapp, A. K., Blair, J. M., and Collins, S. L.: Productivity responses to altered rainfall patterns in a C4dominated grassland, Oecologia, 137, 245-251, 2003.

Feng, X., Porporato, A., and Rodriguez-Iturbe, I.: Changes in rainfall seasonality in the tropics, Nat. Clim. Change, 3, 811-815, 2013

Field, C., Barros, V., Stocker, T., Qin, D., Dokken, D., Ebi, K., Mastrandrea, M., Mach, K., Plattner, G.-K., Allen, S., Tignor, M., and Midgley, P. (Eds.): IPCC, 2012: Managing the Risks of Extreme Events and Disasters to Advance Climate Change Adaptation, A Special Report of Working Groups I and II of the Intergovernmental Panel on Climate Change, Cambridge University Press, Cambridge, UK, and New York, NY, USA, 2012.

Franz, T. E., Caylor, K. K., Nordbotten, J. M., Rodríguez-Iturbe, I., and Celia, M. A.: An ecohydrological approach to predicting regional woody species distribution patterns in dryland ecosystems, Adv. Water Resour., 33, 215-230, 2010.

Gerten, D., Luo, Y., Maire, G. L., Parton, W. J., Keougn, C., Weng, E., Beier, C., Ciais, P., Cramer, W., Dukes, J. S., Hanson, P. J., Knapp, A. A. K., Linder, S., Nepstad, D., Rustad, L., and Sowerby, A.: Modelled effects of precipitation on ecosystem carbon and water dynamics in different climatic zones, Glob. Change Biol., 14, 2365-2379, 2008.

Good, S. P. and Caylor, K. K.: Climatological determinants of woody cover in Africa, Proc. Natl. Acad. Sci. USA, 108, 49024907, 2011.

Graham, E. A., Mulkey, S. S., Kitajima, K., Phillips, N. G., and Wright, S. J.: Cloud cover limits net $\mathrm{CO}_{2}$ uptake and growth of a rainforest tree during tropical rainy seasons, Proc. Natl. Acad. Sci. USA, 100, 572-576, 2003.

Guan, K., Wood, E. F., and Caylor, K. K.: Multi-sensor derivation of regional vegetation fractional cover in Africa, Remote Sens. Environ., 124, 653-665, 2012.
Guan, K., Wolf, A., Medvigy, D., and Caylor, K.: Seasonal coupling of canopy structure and function in African tropical forests and its environmental controls, Ecosphere, 4, 1-21, 2013.

Guan, K., Wood, E. F., Medvigy, D., Pan, M., Caylor, K. K., Sheffield, J., Kimball, J., Xu, X., and Jones, M. O.: Terrestrial hydrological controls on vegetation phenology of African savannas and woodlands, J. Geophys. Res., 119, 1652-1669, 2014.

Hanan, N. P., Tredennick, A. T., Prihodko, L., Bucini, G., and Dohn, J.: Analysis of stable states in global savannas: is the CART pulling the horse?, Glob. Ecol. Biogeogr., 23, 259-263, 2013.

Harper, C. W., Blair, J. M., Fay, P. A., Knapp, A. K., and Carlisle, J. D.: Increased rainfall variability and reduced rainfall amount decreases soil $\mathrm{CO}_{2}$ flux in a grassland ecosystem, Glob. Change Biol., 11, 322-334, 2005.

Heisler-White, J. L., Blair, J. M., Kelly, E. F., Harmoney, K., and Knapp, A. K.: Contingent productivity responses to more extreme rainfall regimes across a grassland biome, Glob. Change Biol. 15, 2894-2904, 2009.

Hely, C., Bremond, L., Alleaume, S., Smith, B., Sykes, M. T., and Guiot, J.: Sensitivity of African biomes to changes in the precipitation regime, Glob. Ecol. Biogeogr., 15, 258-270, 2006.

Higgins, S. I. and Scheiter, S.: Atmospheric $\mathrm{CO}_{2}$ forces abrupt vegetation shifts locally, but not globally, Nature, 488, 209-212, 2012.

Hirota, M., Holmgren, M., Nes, E. H. V., and Scheffer, M.: Global Resilience of Tropical Forest and Savanna to Critical Transitions, Science, 334, 232-235, 2011.

Holmgren, M., Hirota, M., van Nes, E. H., and Scheffer, M.: Effects of interannual climate variability on tropical tree cover, Nat. Clim. Change, 3, 755-758, 2013.

Huffman, G. J., Bolvin, D. T., Nelkin, E. J., Wolff, D. B., Adler, R. F., Bowman, K. P., and Stocker, E. F.: The TRMM Multisatellite Precipitation Analysis (TMPA): Quasi-Global, Multiyear, Combined-Sensor Precipitation Estimates at Fine Scales, J. Hydrometeorol., 8, 38-55, 2007.

Knapp, A. K., Fay, P. A., Blair, J. M., Collins, S. L., Smith, M. D., Carlisle, J. D., Harper, C. W., Danner, B. T., Lett, M. S., and McCarron, J. K.: Rainfall Variability, Carbon Cycling, and Plant Species Diversity in a Mesic Grassland, Science, 298, 22022205, 2002.

Kulmatiski, A. and Beard, K. H.: Woody plant encroachment facilitated by increased precipitation intensity, Nat. Clim. Change, 3, 833-837, 2013.

Lehmann, C. E. R., Archibald, S. A., Hoffmann, W. A., and Bond, W. J.: Deciphering the distribution of the savanna biome, New Phytol., 191, 197-209, 2011.

Markham, C.: Seasonality of precipitation in the United States, Ann. Assoc. Am. Geogr., 60, 593-597, 1970.

Martiny, N., Camberlin, P., Richard, Y., and Philippon, N.: Compared regimes of NDVI and rainfall in semi-arid regions of Africa, Internat. J. Remote Sens., 27, 5201-5223, 2006.

Milly, P.: Potential evaporation and soil moisture in general circulation models, J. Climate, 5, 209-226, 1992.

Miranda, J., Armas, C., Padilla, F., and Pugnaire, F.: Climatic change and rainfall patterns: Effects on semi-arid plant communities of the Iberian Southeast, J. Arid Environ., 75, 1302-1309, 2011. 
O'Gorman, P. A. and Schneider, T.: The physical basis for increases in precipitation extremes in simulations of 21st-century climate change, Proc. Natl. Acad. Sci. USA, 106, 14773-14777, 2009.

Porporato, A., Laio, F., Ridolfi, L., and Rodríguez-Iturbe, I.: Plants in water-controlled ecosystems: active role in hydrologic processes and response to water stress - III. Vegetation water stress, Adv. Water Resour., 24, 725-744, 2001.

Porporato, A., Daly, E., and Rodríguez-Iturbe, I.: Soil Water Balance and Ecosystem Response to Climate Change, Am. Natural., 164, 625-632, 2004.

Robertson, T. R., Bell, C. W., Zak, J. C., and Tissue, D. T.: Precipitation timing and magnitude differentially affect aboveground annual net primary productivity in three perennial species in a Chihuahuan Desert grassland, New Phytol., 181, 230-242, 2009.

Rodríguez-Iturbe, I. and Porporato, A.: Ecohydrology of WaterControlled Ecosystems: Soil Moisture And Plant Dynamics, Cambridge University Press, 2004.

Rodríguez-Iturbe, I., Gupta, V. K., and Waymire, E.: Scale Considerations in the Modeling of Temporal Rainfall, Water Resour. Res. 20, 1611-1619, 1984.

Rodríguez-Iturbe, I., Porporato, A., Ridolfi, L., Isham, V., and Cox, D. R.: Probabilistic Modelling of Water Balance at a Point: The Role of Climate, Soil and Vegetation, Proceedings: Mathematical, Phys. Engin. Sci., 455, 3789-3805, 1999.

Ross, I., Misson, L., Rambal, S., Arneth, A., Scott, R. L., Carrara, A., Cescatti, A., and Genesio, L.: How do variations in the temporal distribution of rainfall events affect ecosystem fluxes in seasonally water-limited Northern Hemisphere shrublands and forests?, Biogeosciences, 9, 1007-1024, doi:10.5194/bg-9-10072012, 2012.

Saha, S., Moorthi, S., Pan, H.-L., Wu, X., Wang, J., Nadiga, S., Tripp, P., Kistler, R., Woollen, J., Behringer, D., Liu, H., Stokes, D., Grumbine, R., Gayno, G., Wang, J., Hou, Y.-T., Chuang, H.Y., Juang, H.-M. H., Sela, J., Iredell, M., Treadon, R., Kleist, D., Delst, P. V., Keyser, D., Derber, J., Ek, M., Meng, J., Wei, H., Yang, R., Lord, S., Dool, H. V. D., Kumar, A., Wang, W., Long, C., Chelliah, M., Feng, Y., Huang, B., Schemm, J.-K., Ebisuzaki, W., Lin, R., Xie, P., Chen, M., Zhou, S., Higgins, W., Zou, C.Z., Liu, Q., Chen, Y., Han, Y., Cucurull, L., Reynolds, R. W., Rutledge, G., and Goldberg, M.: The NCEP Climate Forecast System Reanalysis, Bull. Am. Meteorol. Soc., 91, 1015-1057, 2010.

Sato, H.: Simulation of the vegetation structure and function in a Malaysian tropical rain forest using the individual-based dynamic vegetation model SEIB-DGVM, Forest Ecol. Manage, 257, 2277-2286, 2009.

Sato, H. and Ise, T.: Effect of plant dynamic processes on African vegetation responses to climate change: analysis using the spatially explicit individual-based dynamic global vegetation model (SEIB-DGVM), J. Geophys. Res., 117, G03017, doi:10.1029/2012JG002056, 2012.

Sato, H., Itoh, A., and Kohyama, T.: SEIB-DGVM: A new Dynamic Global Vegetation Model using a spatially explicit individualbased approach, Ecol. Modell., 200, 279-307, 2007.

Sato, H., Kobayashi, H., and Delbart, N.: Simulation study of the vegetation structure and function in eastern Siberian larch forests using the individual-based vegetation model SEIB-DGVM, Forest Ecol. Manag., 259, 301-311, 2010.
Scanlon, T. M., Caylor, K. K., Manfreda, S., Levin, S. A., and Rodriguez-Iturbe, I.: Dynamic response of grass cover to rainfall variability: implications for the function and persistence of savanna ecosystems, Adv. Water Resour., 28, 291-302, 2005.

Scholes, R. J. and Archer, S. R.: Tree-Grass Interactions in Savannas, Ann. Rev. Ecol. System., 28, 517-544, 1997.

Seth, A., Rauscher, S. A., Biasutti, M., Giannini, A., Camargo, S. J., and Rojas, M.: CMIP5 Projected Changes in the Annual Cycle of Precipitation in Monsoon Regions, J. Climate, 26, 7328-7351, 2013.

Sheffield, J., Goteti, G., and Wood, E. F.: Development of a 50-Year High-Resolution Global Dataset of Meteorological Forcings for Land Surface Modeling, J. Climate, 19, 3088-3111, 2006.

Shongwe, M. E., van Oldenborgh, G. J., van den Hurk, B. J. J. M., de Boer, B., Coelho, C. A. S., and van Aalst, M. K.: Projected Changes in Mean and Extreme Precipitation in Africa under Global Warming - Part I: Southern Africa, J. Climate, 22, 3819-3837, 2009.

Shugart, H. H.: Terrestrial ecosystems in changing environments, Cambridge University Press, United Kingdom, 1998.

Staver, A. C., Archibald, S., and Levin, S. A.: The Global Extent and Determinants of Savanna and Forest as Alternative Biome States, Science 334, 230-232, 2011.

Stocker, T. F., Qin, D., Plattner, G.-K., Tignor, M., Allen, S. K., Boschung, J., Nauels, A., Xia, Y., Bex, V., and Midgley, P. M. (Ed.): IPCC, 2013: Climate Change 2013: The Physical Science Basis, Contribution of Working Group I to the Fifth Assessment Report of the Intergovernmental Panel on Climate Change, Cambridge University Press, Cambridge, United Kingdom and New York, NY, USA, 2013.

Svejcar, T., Bates, J., Angell, R., and Miller, R.: The influence of precipitation timing on the sagebrush steppe ecosystem, in: Changing Precipitation Regimes andTerrestrial Ecosystems, edited by: McPherson, G. and Weltzin, J., University of Arizona Press, Tucson, AZ 237 pp., 2003.

Thomey, M. L., Collins, S. L., Vargas, R., Johnson, J. E., Brown, R. F., Natvig, D. O., and Friggens, M. T.: Effect of precipitation variability on net primary production and soil respiration in a Chihuahuan Desert grassland, Glob. Change Biol., 17, 15051515, 2011.

Trenberth, K. E., Dai, A., Rasmussen, R. M., and Parsons, D. B.: The Changing Character of Precipitation, Bull. Am. Meterol. Soc., 84, 1205-1217, 2003.

van Schaik, C. P., Terborgh, J. W., and Wright, S. J.: The Phenology of Tropical Forests: Adaptive Significance and Consequences for PrimaryConsumers, Ann. Rev. Ecol. System., 24, 353-377, 1993.

Vincens, A., Garcin, Y., and Buchet, G.: Influence of rainfall seasonality on African lowland vegetation during the Late Quaternary: pollen evidence from Lake Masoko, Tanzania, J. Biogeogr., 34, 1274-1288, 2007.

Weltzin, J. F., Loik, M. E., Schwinning, S., Williams, D. G., Fay, P. A., Haddad, B. M., Harte, J., Huxman, T. E., Knapp, A. K., Lin, G., Pockman, W. T., Shaw, M. R., Small, E. E., Smith, M. D., Smith, S. D., Tissue, D. T., and Zak, J. C.: Assessing the Response of Terrestrial Ecosystems to Potential Changes in Precipitation, BioScience, 53, 941-952, 2003. 
Williams, C. A. and Albertson, J. D.: Dynamical effects of the statistical structure of annual rainfall on dryland vegetation, Glob. Change Biol., 12, 777-792, 2006.

Zhang, X., Friedl, M. A., Schaaf, C. B., Strahler, A. H., and Liu, Z.: Monitoring the response of vegetation phenology to precipitation in Africa by coupling MODIS and TRMM instruments, J. Geophys. Res., 110, D12103, doi:10.1029/2004JD005263, 2005.
Zhang, Y., Moran, M. S., Nearing, M. A., Campos, G. E. P., Huete, A. R., Buda, A. R., Bosch, D. D., Gunter, S. A., Kitchen, S. G., McNab, W. H., Morgan, J. A., McClaran, M. P., Montoya, D. S., Peters, D. P., and Starks, P. J.: Extreme precipitation patterns and reductions of terrestrial ecosystem production across biomes, J. Geophys. Res.-Biogeosciences, 118, 148-157, 2013. 